Revista Destaques Acadêmicos, Lajeado, v. 11, n. 2, 2019. ISSN 2176-3070

DOI: http://dx.doi.org/10.22410/issn.2176-3070.v11i2a2019.1986

http://www.univates.br/revistas

\title{
STRESS E ESTRATÉGIAS DE COPING: UM ESTUDO COM UNIVERSITÁRIOS DOS CURSOS DE FISIOTERAPIA E CIÊNCIA DA COMPUTAÇÃO
}

\author{
Daianna Carboni de Souza ${ }^{1}$, Isaac dos Santos Teixeira Junior ${ }^{2}$, Sideli Biazzi ${ }^{3}$
}

Resumo: O presente artigo buscou identificar possível relação entre a percepção do stress com o uso de estratégias de coping. A pesquisa estudou uma população de 106 alunos do $6^{\circ}$ e $8^{\circ}$ semestres dos cursos de Fisioterapia e Ciência da Computação, de um centro universitário, localizado em São Paulo/BR, por meio da Escala Visual Analógica do Stress e COPE-BREVE, avaliando o impacto da percepção do stress e o uso de estratégias de coping na saúde dos estudantes. Os dados revelaram que os alunos de Fisioterapia são em sua maioria do sexo feminino $(83,33 \%)$ com percepção do nível de stress moderado (46,29\%) e com um repertório reduzido no uso de estratégias de enfrentamento do stress. Já o curso de Ciência da Computação, tem prevalência de alunos do sexo masculino (90,38\%) e 42,3\% percebem-se sem stress, apresentando um repertório diversificado no uso das estratégias de enfrentamento. Conclui-se que as estratégias de coping desempenham um importante papel quanto a percepção do nível de stress. O uso eficaz de estratégias de enfrentamento permite ao discente competências para diminuir os estressores. Os resultados observados indicam oportunidade de aprofundamento do tema, ampliando o repertório de soluções em prol da melhoria de qualidade de vida do discente.

Palavra-chave: Stress. Universitário. Coping.

\section{INTRODUÇÃO}

O seguinte trabalho tem como objetivo identificar o nível de stress e as estratégias de coping utilizadas pelos universitários dos cursos de Fisioterapia e Ciência da Computação de um centro universitário da cidade de São Paulo.

1 Acadêmica do curso de Psicologia do Centro Universitário Adventista de São Paulo, São Paulo/SP.

2 Acadêmico do curso de Psicologia do Centro Universitário Adventista de São Paulo, São Paulo/SP.

3 Doutora em Psicologia Clínica (PUC), orientadora e docente dos cursos de graduação e pósgraduação do Centro Universitário Adventista de São Paulo, São Paulo/SP. 
O stress, atualmente é um tema muito discutido na mídia, nas organizações, nos meios sociais e através de pesquisas científicas. Há evidências que o stress vem sendo destaque nas discussões científicas, pois é um fator que leva ao adoecimento de indivíduos em vários contextos sociais, porém poucos estudos relacionam stress com a vida acadêmica (BORINE et al., 2015).

Durante a formação, são vários fatores estressores que podem desencadear uma alteração no desempenho do estudante como: cobrança de professores, avaliações constantes, hábitos individuais e responsabilidades que o aluno cumpre que podem alterar a capacidade de raciocínio, memorização e interesse do jovem em relação ao processo da aprendizagem.

Com efeito, o stress encontra-se negativamente associado à percepção que o estudante tem de si e de suas competências escolares (MONTEIRO et al., 2007).

\section{DEFININDO STRESS}

Selye (apud FILGUEIRAS; HIPPERT, 1999) conceitua o stress como um comportamento manifestado perante um acontecimento, não específico do corpo, a qualquer exigência que lhe seja feita.

Para Lipp (2002) o stress pode ser descrito como uma reação muito complexa, composta de alterações psicofisiológicas que ocorrem quando a pessoa é forçada a encarar situações que ultrapassem sua habilidade de enfrentamento.

O stress pode ocorrer em diferentes níveis, de uma forma mais transitória ou grave; no último caso, resulta em consequências que irão afetar a saúde do indivíduo. Conforme Selye (apud FILGUEIRAS; HIPPERT, 1999) divide-se o stress em três fases, como detalhado a seguir.

O modelo trifásico do stress se divide em: alerta ou alarme, resistência e quase exaustão. A fase de alerta/alarme é caracterizada por manifestações agudas como taquicardia, sudorese, cefaleia, palidez, hipertensão, fadiga, insônia, dificuldade respiratória, inapetência, apertar dos maxilares, pressão no peito e estômago tenso; na fase da resistência, quando as manifestações agudas desaparecem, ocorre a mobilização específica de um órgão e também o estabelecimento dos sintomas de caráter psicossocial. Por fim, na fase de quase exaustão, ocorre à volta das reações da primeira fase (alerta) que podem induzir ao colapso energético do órgão vulnerável, o qual chamamos de "órgão de choque", desencadeando uma patologia orgânica ou um óbito súbito.

Também é importante entender que os estressores podem ser externos e internos. Os primeiros têm a ver com as condições externas que afetam o organismo e são representados por situações vividas, tais como: pressões de grupo, insegurança quanto ao desempenho acadêmico, responsabilidade fora de controle, situação econômica, competição, excesso de trabalho/atividades, problemas familiares, doenças, morte na família ou problemas afetivos. 
Os estressores externos também podem se constituir de eventos positivos relacionados a mudanças, tais como: casamento e promoção no trabalho (LIPP, 2000; MARRAS; VELOSO, 2012).

Para Lipp (2000) os estressores internos são os que fazem parte do contexto subjetivo do indivíduo, como: cognições, sentimentos, forma de perceber o mundo, nível de assertividade, crenças, valores, padrões de comportamento, vulnerabilidades e esquemas de reações à vida.

O que fica nítido aqui é que não existe uma determinante específica para os sintomas de stress e sua ocorrência. Essa avaliação está sujeita a forma como o indivíduo interpreta e reage, podendo envolver componentes comportamentais, afetivos, cognitivos e fisiológicos, além da capacidade do seu organismo de atender às exigências situacionais (MARRAS; VELOSO, 2012).

A presença e intensidade das respostas variam dependendo da avaliação que o indivíduo fizer da situação, assim como de suas experiências prévias adquiridas para lidar com a situação (LIPP, 2002).

Dessa forma, os mecanismos de enfrentamento são especialmente importantes porque podem limitar a duração e a magnitude das respostas ao stress crônico ou podem gerar respostas prolongadas ao stress, mesmo na ausência do estímulo estressor (por exemplo: desordens de estresse póstraumático subsequentes a severas experiências traumáticas ou, de uma forma mais suave, raiva/distúrbios de humor persistentes após um conflito social).

Assim, além de estudarmos os eventos estressores e suas reações biopsicossociais, é importante nos aprofundarmos sobre quais estratégias de coping os universitários estão utilizando por meio deste.

Estudos com a população discente universitária brasileira revelaram que a vida acadêmica é caracterizada como uma situação estressante, uma vez que esse período é constituído pela cobrança de professores e hábitos pessoais que alteram o desempenho acadêmico, como os vícios, adicionando o fato de ser um período de inúmeras transições (SANTOS et al., 2012).

Nesse mesmo artigo, realizou-se um estudo com 58 estudantes de Fisioterapia e apresentaram que $91,4 \%$ dos acadêmicos consideravam suas atividades na universidade como fontes catalizadoras de stress; as variáveis com maior predominância na intensidade de stress externo citadas são: incertezas quanto ao futuro profissional $(50 \%)$, falta de tempo para atividades de lazer $(50 \%)$, carga horária elevada do curso $(46,6 \%)$, volume elevado de matérias para estudar $(43,1 \%)$, número de horas de sono insuficientes $(36,2 \%)$, dificuldade na gestão do tempo (34,5\%). Já o ensino/aprendizagem focados na memorização constituíram 32,8\% dos fatores estressantes.

Confirmando esses dados, Ramos e Carvalho (2007) apresentam que as exigências acadêmicas, as relações interpessoais, os problemas financeiros e os problemas relacionados com a sexualidade são entendidos como razões primárias para a existência do stress nos universitários. 
Assim como os estudantes de Fisioterapia, os estudantes de Ciência da Computação também estão sujeitos a eventos estressores. De forma geral, Rosen (apud TEIXEIRA; AZEVEDO, 2017, p. 114) define "o tecnoestress como sendo o resultado da convivência cada vez maior das pessoas com a tecnologia". Se comparados os estudantes dos dois cursos, os de Ciência da Computação estão em maior contato com aparelhos tecnológicos que os de Fisioterapia. Ainda no mesmo artigo, os autores afirmam:

Tratando especificamente dos profissionais da Tecnologia da Informação, observa-se que os mesmos estão constantemente sobre pressão, visto que precisam atualiza-se, qualificar-se, manter-se sempre informados, passam horas e mais horas trabalhando com máquinas, resolvendo problemas, traçando estratégias, coletando, processando e analisando informações, tudo na "linguagem de máquinas". Este tipo de comportamento pode levá-los ao surgimento de transtornos relacionados ao estresse, podendo acarretar depressão, fobias e demais transtornos de ansiedade. A relação interpessoal também pode ser prejudicada, pelo excesso de objetividade da linguagem robótica, resultando em um declínio na saúde e consequentemente na sua qualidade de vida (TEIXEIRA; AZEVEDO, 2017, p. 114).

Claramente esse trecho nos leva a crer que, assim como os profissionais de Tecnologia da Informação estão sofrendo influências pelo contato constante com as máquinas e suas linguagens, aqueles que estão concluindo a graduação também estão, logo, sofrem dos mesmos efeitos.

De acordo com Teixeira e Azevedo (2017) em pesquisa realizada ao redor do mundo com mais de três mil profissionais da área de Tecnologia da Informação, revelou-se que estes estão mais propensos a sofrer com o stress do que os de outras áreas. Segundo o levantamento, 97\% dos profissionais de TI alegam sofrer de stress diariamente em seu ambiente de trabalho. Isso nos leva a pensar em quais as situações de stress os estudantes de Ciência da Computação estão passando e o que eles têm feito para enfrentar esses eventos estressores.

\section{DEFININDO COPING}

Segundo Dell'Aglio (2003) coping corresponde a um agrupamento de estratégias, cognitivas e comportamentais, que os indivíduos utilizam em situações adversas, com o objetivo de lidar com demandas específicas, internas ou externas, que ocorrem em situações de stress e são avaliadas como excedentes aos recursos pessoais.

Coping é definido como um conjunto de esforços, cognitivos e comportamentais, utilizado pelos indivíduos com o objetivo de lidar com demandas específicas, internas ou externas, que surgem 
em situações de stress e são avaliadas como sobrecarregando ou excedendo seus recursos pessoais (LAZARUS; FOLKMAN apud ANTONIAZZI et al., 1998, p. 276).

Antoniazzi et al. (1999) buscaram enfatizar os comportamentos de coping e seus determinantes cognitivos e situacionais. Ainda, conceituaram coping como uma transição entre pessoa e o ambiente, enfatizando o processo e os traços de personalidade.

Segundo Antoniazzi et al. (1998) as estratégias de coping têm sido vinculadas a fatores situacionais. Além disso, apontam que estas estratégias podem mudar de momento para momento, durante os estágios de uma situação estressante.

Para Antoniazzi et al. (1999) a psicologia do ego entende o coping como um mecanismo de defesa, ou seja, de forma interna e inconsciente, sendo um modo de lidar com os conflitos sexuais e agressivos. Ainda no mesmo artigo, adicionam que eventos externos e ambientais, foram posteriormente incluídos como possíveis provocadores dos processos de coping, classificados hierarquicamente dos mais imaturos aos mais sofisticados.

Estudos mais recentes têm-se voltado para as convergências entre o coping e a personalidade. De acordo com o mesmo artigo, os autores propõem evidências que indicam o quanto os fatores situacionais não são capazes de explicar toda a variação nas estratégias de coping utilizadas pelos indivíduos.

Para Ramos et al. (2015) dividem-se em duas estratégias funcionais: coping centrado na emoção e coping centrado no problema. O primeiro referese como o indivíduo autorregula as emoções negativas que estão ligadas ao evento estressor, enquanto que o segundo modelo caracteriza os indivíduos que priorizam gerenciar e alterar os aspectos de uma pessoa, de um ambiente ou de uma situação avaliada como estressora.

Em estudo com universitários, Carlotto et al. (2015) revelam que as estratégias mais funcionais para a adaptação à faculdade são as estratégias direcionada a resoluções de problemas e suporte social. Em contrapartida, estratégias voltadas para a evitação e esquiva, mostram-se relacionadas a índices inferiores de adaptação ao ensino superior.

Ainda no mesmo artigo, com relação ao gênero, os autores apontam que as mulheres tendem a usar mais estratégias com foco na emoção e apoio social, enquanto que os homens costumam utilizar estratégias baseadas no problema.

Ramos e Carvalho (2007) apresentam vários estudos sobre coping, entre eles um realizado por Toray e Cooley (1998) que tinha por objetivo conhecer as estratégias de coping utilizadas por um grupo feminino de 271 jovens universitárias dos primeiros e últimos anos; a conclusão foi que as estudantes do primeiro ano usavam estratégias de distanciamento, evitamento e 
autoisolamento, enquanto que as estudantes do último ano usavam estratégias voltadas para a resolução do problema.

Assim, estudos sobre os temas são importantes para o desenvolvimento de programas que promovam o controle do stress, tanto para prevenir quanto para tratar daqueles que já se apresentam estressados. Nesse contexto, o objetivo do presente estudo é comparar os níveis de stress e coping em universitários, de modo a investigar a associação do stress com as estratégias utilizadas.

\subsection{Hipótese}

Acreditamos que exista diferença na forma como os dois grupos enfrentam o stress, pois os cursos na área de saúde oferecem técnicas para lidar com o ser humano e que poderiam ser eventualmente incorporadas para a resolução de eventos estressores da vida pessoal. Enquanto que os cursos tecnológicos não têm essa interface humana com o ser humano, assim, possivelmente não oferecem essas estratégias ao indivíduo.

\subsection{Objetivo geral}

Avaliar a percepção do nível de stress em universitários do curso de Fisioterapia e Ciência da Computação, buscando possível relação com o uso de estratégias de coping.

\subsection{Objetivos específicos} pelos

a) Identificar quais são as estratégias mais frequentes de coping utilizadas universitários.

b) Verificar se há variação das estratégias em função dos cursos e de sexo.

c) Compreender a relação entre a percepção do nível de stress e a utilização das estratégias de coping.

\section{MÉTODO}

\subsection{Tipo de pesquisa}

A pesquisa é de campo de natureza quantitativa.

\subsection{População}

A população consistiu-se num total de 106 acadêmicos dos cursos de Fisioterapia e Ciência da Computação de um centro universitário, localizado na cidade de São Paulo. 


\subsection{Local da coleta}

A coleta foi realizada nas salas de aula dos $6^{\circ}$ e $8^{\circ}$ semestres dos cursos de Fisioterapia e Ciência da Computação.

\subsection{Critérios de Inclusão}

Os alunos que foram incluídos na pesquisa estavam matriculados no $6^{\circ}$ e $8^{\circ}$ semestres, assinaram o Termo de Consentimento Livre e Esclarecido e preencheram todos os instrumentos corretamente.

\subsection{Critérios de Exclusão}

Foram excluídos aqueles que por motivos pessoais não quiseram participar, não assinaram o Termo de Consentimento Livre e Esclarecido e não preencheram corretamente todos os instrumentos.

\subsection{Instrumentos}

Questionário de caracterização da amostra: Foi utilizado para conhecimento do perfil dos participantes do estudo, incluindo sexo, estado civil, idade e se exercia atividade laboral ou não.

Escala Visual Analógica - EVA do Stress: A Escala Visual Analógica do Stress, adaptada por Esdras Vasconcellos, é um instrumento de autoavaliação da intensidade do stress percebido, na qual o sujeito escolhe uma cor que mais associe ao seu estado no momento. A escala é progressiva, partindo das cores branca (1), azul (2), amarela (3), laranja (4) e vermelha (5), que representa "máximo stress". A escala demonstra que o valor escolhido pelo sujeito reflete a intensidade do stress e sua evolução. A EVA foi utilizada nesta pesquisa para verificar a percepção do nível de stress que os universitários se encontravam no momento da aplicação.

A Escala de Cope Breve foi desenvolvida por Ribeiro e Rodrigues (2004), na tentativa de diminuir a sobrecarga dos respondentes frente a instrumentos relativamente longos, como desenvolvido inicialmente por Lazarus e Folkman com 67 questões. Essa versão reduzida é constituída por 28 itens, tendo por objetivo identificar, também, quais são as estratégias de coping utilizadas pelos participantes.

\subsection{Procedimentos}

A partir da aprovação do projeto pelo comitê de ética, foram adotados os seguintes procedimentos: apresentamos o projeto aos coordenadores dos cursos de Ciência da Computação e de Fisioterapia e formalizamos a permissão da coleta de dados autorizada por eles. Contatamos o professor regente da aula indicada pelo coordenador para a aplicação dos instrumentos. Pela 
manhã aplicamos no curso de Fisioterapia e à noite com o curso da Ciência da Computação. Foram aplicados os três instrumentos em 1 aula, totalizando, aproximadamente, 45 minutos. Em sala de aula, explicamos aos alunos a finalidade do nosso estudo. Entregamos o termo de consentimento livre e esclarecido, lemos em voz alta para todos, a fim de explanar possíveis dúvidas que pudessem surgir. Somente aqueles que quiseram participar permaneceram na sala, os outros alunos foram liberados. Após a assinatura do TCLE, o questionário sócio demográfico foi entregue. Após o preenchimento do questionário de caracterização da amostra foi apresentada aos alunos a Escala Visual Analógica. Para aplicação da Escala Visual Analógica do stress, passamos nas fileiras para que os alunos identificassem qual a cor indicava o seu nível de stress naquele momento. Em caso de indicação do vermelho (máximo stress), o aluno foi orientado a responder, em uma única palavra, qual o motivo do seu stress. Após a aplicação do EVA entregamos o instrumento do Cope Breve. Logo em seguida lemos em voz alta o instrumento para que não houvesse dúvidas no seu preenchimento. Para finalizar, pegamos os instrumentos respondidos e agradecemos a contribuição de todos.

\subsection{Análise dos dados}

Os dados coletados foram apresentados em média e desvio-padrão. A simetria dos dados foi analisada por meio do teste de Kolmogorov-Smirnov. A comparação do stress entre os componentes do grupo tratado foi realizada por meio do teste " $\mathrm{t}$ " ou análise de variância respeitando o número de variáveis que foram analisadas. A comparação do stress entre os grupos foi feita por meio da análise de variância, com medidas repetidas. Para identificar o peso de cada variável (estratégia) como contribuinte controle do stress foi realizada a regressão multivariada. As correlações foram feitas por matriz, considerando $p$ $\leq 0,05$ como significância estatística.

\subsection{Questões éticas da pesquisa}

De acordo com a resolução 510 do Conselho Nacional de Saúde, artigo primeiro, inciso VIII, parágrafo $1^{\circ}$, por se tratar de um trabalho de conclusão de curso, este foi apresentado ao sistema CEP/CONEP, obtendo o Certificado de Apresentação para Apreciação Ética (CAAE): 78751617.7.0000.5377.

\section{RESULTADOS}

A Tabela 1 mostra que 106 indivíduos foram avaliados, 47,17\% são do sexo feminino e $52,83 \%$, são do sexo masculino. Destes $58,49 \%$ estavam na faixa etária dos 19 a 21 anos, $27,35 \%$ estavam entre os 22 e 24 anos, $8,49 \%$ estavam na faixa etária dos 25 e 27 anos e 5,66\% estavam entre 28 e 38 anos. No que diz respeito a atividade laboral $66,98 \%$ dos sujeitos trabalham. Sobre o estado civil, observamos que $85,85 \%$ são solteiros e $14,15 \%$ são casados. 
Tabela 1: Descrição das características sociodemográficas dos alunos

\begin{tabular}{c|c}
\hline Variáveis & $\mathbf{N}=\mathbf{1 0 6}$ \\
\hline Idade (anos) & $62(58,49)$ \\
\hline $19-21(\%)$ & $29(27,35)$ \\
\hline $22-24(\%)$ & $9(8,49)$ \\
\hline $25-27(\%)$ & $6(5,66)$ \\
\hline $28-38(\%)$ & \\
\hline Sexo & $56(52,83)$ \\
\hline Masculino (\%) & $50(47,17)$ \\
\hline Feminino (\%) & $15(14,15)$ \\
\hline E. Civil & $90(84,90)$ \\
\hline Casado (\%) & $1(0,94)$ \\
\hline Solteiro (\%) & \\
\hline União Estável (\%) & $71(66,98)$ \\
\hline Trabalho & $35(33,02)$ \\
\hline Sim (\%) &
\end{tabular}

A Tabela 2 apresenta os dados quanto a percepção do nível de stress dos cursos de Ciência da Computação e Fisioterapia, buscando uma relação quanto ao sexo. Foi observado que $39,29 \%$ dos homens estão se percebendo sem stress e que $42 \%$ das mulheres percebem-se com nível de stress moderado, mostrando que as mulheres estão mais vulneráveis ao stress do que os homens.

Tabela 2: Dados de ambos cursos separado por sexo quanto a percepção do nível de stress.

\begin{tabular}{c|c|c|c}
\hline Variáveis & $\mathbf{N}=\mathbf{5 6}$ & Variáveis & $\mathbf{N}=\mathbf{5 0}$ \\
\hline Sexo & & Sexo & \\
\hline Masculino (\%) & 52,83 & Feminino (\%) & 47,16 \\
\hline $\begin{array}{c}\text { Percepção do nível de } \\
\text { stress }\end{array}$ & & $\begin{array}{c}\text { Percepção do nível } \\
\text { de stress }\end{array}$ & \\
\hline Sem stress (\%) & $22(39,29)$ & Sem stress (\%) & $17(34)$ \\
\hline Moderado (\%) & $19(33,93)$ & Moderado (\%) & $21(42)$ \\
\hline Elevado (\%) & $15(26,79)$ & Elevado $(\%)$ & $12(24)$ \\
\hline
\end{tabular}

A Tabela 3 apresenta os dados dos discentes do curso de Fisioterapia. Observamos que 16,66\% são do sexo masculino e $83,34 \%$ são do sexo feminino, 
destes 31,47\% perceberam-se sem stress e 46,29\% perceberam-se com nível de stress moderados e $22,21 \%$ com nível elevado de stress.

Tabela 3: Dados do curso de Fisioterapia

\begin{tabular}{c|c}
\hline Variáveis & $\mathbf{N = 5 4}$ \\
\hline Sexo & $9(16,66)$ \\
\hline Masculino (\%) & $45(83,34)$ \\
\hline Feminino (\%) & \\
\hline Percepção do nível de stress & $17(31,47)$ \\
\hline Sem stress (\%) & $25(46,29)$ \\
\hline Moderado (\%) & $12(22,22)$ \\
\hline Elevado (\%) &
\end{tabular}

A Tabela 4 refere-se aos discentes do curso de Ciência da Computação. Observamos que $90,39 \%$ são do sexo masculino e $9,61 \%$ do sexo feminino. Quanto à percepção do stress, 42,3\% perceberam-se sem stress; $28,84 \%$ com stress moderados e $28,84 \%$ com stress elevado.

Tabela 4: Dados dos alunos do curso de Ciência da Computação

\begin{tabular}{c|c}
\hline Variáveis & $\mathbf{N}=\mathbf{5 2}$ \\
\hline Sexo & \\
\hline Masculino (\%) & $47(90,39)$ \\
\hline Feminino (\%) & $5(9,61)$ \\
\hline Percepção do nível de stress & \\
\hline Sem stress (\%) & $22(42,30)$ \\
\hline Moderado (\%) & $15(28,84)$ \\
\hline Elevado (\%) & $15(28,84)$ \\
\hline
\end{tabular}

A Tabela 5 mostra a comparação das estratégias de coping entre os cursos de Ciência da Computação e Fisioterapia. De todas as estratégias avaliadas, as estratégias focadas no problema que foram consideradas significativas são: busco outras atividades para me distrair da situação $(p=0,04)$; procuro apoio emocional de alguém ( $\mathrm{p}=0,0006)$; peço conselhos e ajuda a outras pessoas para enfrentar melhor a situação $(p=0,005)$ e também peço conselhos e ajuda a pessoas que passaram pelo mesmo $(\mathrm{p}=0,02)$; enquanto as estratégias focadas na emoção são: sinto e expresso os meus sentimentos de aborrecimento $(\mathrm{p}=0,01)$; enfrento a situação levando-a para a brincadeira $(p=0,02)$; fico aborrecido e expresso os meus sentimentos (emoções) $(\mathrm{p}=0,006)$; tento encontrar conforto na minha religião ou crença espiritual $(p=0,0001)$ e rezo ou medito $(p=0,0001)$. 
Tabela 5: Comparação das estratégias de coping entre os cursos de Ciência da Computação e Fisioterapia

\begin{tabular}{|c|c|c|c|}
\hline & $\begin{array}{l}\text { Ciência da } \\
\text { Computação }\end{array}$ & Fisioterapia & \\
\hline Estratégias (Focada no problema) & $\begin{array}{l}\text { Média } \pm \\
\text { Desvio } \\
\text { Padrão }\end{array}$ & $\begin{array}{l}\text { Média } \pm \\
\text { Desvio } \\
\text { Padrão }\end{array}$ & $\mathbf{P}$ \\
\hline $\begin{array}{l}\text { Busco outras atividades para me distrair da } \\
\text { situação }\end{array}$ & $1,64 \pm 0,96$ & $1,96 \pm 0,88$ & 0,04 \\
\hline Procuro apoio emocional de alguém & $1,51 \pm 1,08$ & $0,84 \pm 0,99$ & 0,0006 \\
\hline $\begin{array}{l}\text { Tomo medidas para tentar melhorar a minha } \\
\text { situação }\end{array}$ & $2,20 \pm 0,77$ & $2,03 \pm 0,71$ & 0,13 \\
\hline $\begin{array}{l}\text { Tento analisar a situação de maneira } \\
\text { diferente, de forma } \\
\text { a torná-la mais positiva }\end{array}$ & $1,94 \pm 0,78$ & $1,92 \pm 0,81$ & 0,44 \\
\hline $\begin{array}{l}\text { Tento encontrar uma estratégia que me ajude } \\
\text { no que tenho que fazer }\end{array}$ & $2,22 \pm 0,80$ & $2,19 \pm 0,62$ & 0,41 \\
\hline Procuro o conforto e compreensão de alguém & $1,75 \pm 0,98$ & $0,84 \pm 0,93$ & 1,95 \\
\hline $\begin{array}{l}\text { Procuro algo positivo em tudo o que está } \\
\text { acontecendo }\end{array}$ & $1,75 \pm 1,07$ & $1,63 \pm 0,92$ & 0,26 \\
\hline $\begin{array}{l}\text { Tento aceitar as coisas tal como estão } \\
\text { acontecendo }\end{array}$ & $1,54 \pm 0,83$ & $1,75 \pm 0,83$ & 0,1 \\
\hline Tento aprender a viver com a situação & $1,83 \pm 0,89$ & $1,76 \pm 0,92$ & 0,35 \\
\hline $\begin{array}{l}\text { Penso muito sobre a melhor forma de lidar } \\
\text { com a situação }\end{array}$ & $2,31 \pm 0,78$ & $2,25 \pm 0,71$ & 0,32 \\
\hline $\begin{array}{l}\text { Peço conselhos e ajuda a outras pessoas para } \\
\text { enfrentar melhor } \\
\text { a situação }\end{array}$ & $1,05 \pm 0,84$ & $1,26 \pm 0,97$ & 0,005 \\
\hline $\begin{array}{l}\text { Peço conselhos e ajuda a pessoas que } \\
\text { passaram pelo mesmo }\end{array}$ & $1,64 \pm 0,98$ & $1,26 \pm 1,05$ & 0,02 \\
\hline \multicolumn{4}{|l|}{ Estratégias (Focada no emoção) } \\
\hline $\begin{array}{l}\text { Concentro os meus esforços para fazer } \\
\text { alguma coisa que me } \\
\text { permita enfrentar a situação }\end{array}$ & $1,81 \pm 0,92$ & $1,86 \pm 0,79$ & 0,38 \\
\hline Digo para mim mesmo: “Isso não é verdade!" & $0,92 \pm 0,95$ & $0,69 \pm 1,00$ & 0,11 \\
\hline $\begin{array}{l}\text { Uso álcool ou outras drogas para me sentir } \\
\text { melhor }\end{array}$ & $0,22 \pm 0,45$ & $0,19 \pm 0,68$ & 0,39 \\
\hline $\begin{array}{l}\text { Simplesmente desisto de tentar atingir o meu } \\
\text { objetivo }\end{array}$ & $0,53 \pm 0,80$ & $0,59 \pm 0,79$ & 0,35 \\
\hline $\begin{array}{l}\text { Recuso-me a acreditar que isto esteja } \\
\text { acontecendo desta forma comigo }\end{array}$ & $0,90 \pm 1,02$ & $0,69 \pm 0,87$ & 0,12 \\
\hline $\begin{array}{l}\text { Sinto e expresso os meus sentimentos de } \\
\text { aborrecimento }\end{array}$ & $1,87 \pm 0,90$ & $1,44 \pm 0,97$ & 0,01 \\
\hline
\end{tabular}




\begin{tabular}{l|c|c|c}
\hline & $\begin{array}{c}\text { Ciência da } \\
\text { Computação }\end{array}$ & Fisioterapia & \\
\hline $\begin{array}{l}\text { Uso álcool ou outras drogas para me ajudar a } \\
\text { enfrentar os problemas }\end{array}$ & $1,16 \pm 0,41$ & $0,13 \pm 0,52$ & 0,36 \\
\hline Desisto de me esforçar para obter o que quero & $0,38 \pm 0,70$ & $0,61 \pm 0,79$ & 0,06 \\
\hline $\begin{array}{l}\text { Enfrento a situação levando-a para a } \\
\text { brincadeira }\end{array}$ & $1,11 \pm 1,01$ & $\mathbf{1 , 5} \pm \mathbf{0 , 9 8}$ & $\mathbf{0 , 0 2}$ \\
\hline $\begin{array}{l}\text { Faço outras coisas para pensar menos na } \\
\text { situação, } \\
\text { tal como ir ao cinema, ver TV, ler, sonhar, ou } \\
\text { ir às compras }\end{array}$ & $1,64 \pm 1,07$ & $1,84 \pm 1,05$ & 0,17 \\
\hline $\begin{array}{l}\text { Fico aborrecido e expresso os meus } \\
\text { sentimentos (emoções) }\end{array}$ & $\mathbf{1 , 8 8 \pm \mathbf { 1 , 0 4 }}$ & $1,38 \pm 1,01$ & $\mathbf{0 , 0 0 6}$ \\
\hline $\begin{array}{l}\text { Tento encontrar conforto na minha religião } \\
\text { ou crença espiritual }\end{array}$ & $\mathbf{2 , 3 3 \pm \mathbf { 0 , 8 3 }}$ & $1,51 \pm 1,14$ & $\mathbf{0 , 0 0 0 1}$ \\
\hline Rezo ou medito & $\mathbf{2 , 3 7 \pm \mathbf { 0 , 8 8 }}$ & $1,51 \pm 1,11$ & $\mathbf{0 , 0 0 0 1}$ \\
\hline Enfrento a situação com humor & $1,57 \pm 1,02$ & $1,78 \pm 0,84$ & 0,12 \\
\hline Faço crítica a mim mesmo & $1,74 \pm 1,03$ & $1,78 \pm 1,05$ & 0,4 \\
\hline Culpo-me pelo o que está acontecendo & $1,35 \pm 0,94$ & $1,30 \pm 1,02$ & 0,4 \\
\hline P* $\leq 05$ & & & \\
\hline
\end{tabular}

A Tabela 6 revela que é significativo nos discentes do curso de Ciência da Computação, que exercem atividade laboral, as seguintes estratégias focadas no problema: procuro conforto e compreensão de alguém $(\mathrm{p}=0,04)$ e tento aprender a viver com a situação $(p=0,04)$. As estratégias focadas na emoção foram: fico aborrecido e expresso os meus sentimentos $(p=0,03)$; tento encontrar conforto na minha religião ou crença espiritual $(p=0,01)$; rezo ou medito $(p=0,04)$. Não houveram dados significativos quanto aos alunos que não exercem atividade laboral (Tabela 6).

Tabela 6: Dados do curso Ciência da Computação em relação ao trabalho

\begin{tabular}{l|c|c|c}
\hline & $\begin{array}{c}\text { Exerce } \\
\text { atividade } \\
\text { laboral }\end{array}$ & $\begin{array}{c}\text { Não exerce } \\
\text { atividade } \\
\text { laboral }\end{array}$ & \\
\hline $\begin{array}{c}\text { Estratégias (Focada no } \\
\text { problema) }\end{array}$ & $\begin{array}{c}\text { Média / Desvio } \\
\text { Padrão }\end{array}$ & $\begin{array}{c}\text { Média / Desvio } \\
\text { Padrão }\end{array}$ & $\mathbf{P}$ \\
\hline $\begin{array}{l}\text { Procuro conforto e compreensão } \\
\text { de alguém }\end{array}$ & $\mathbf{1 , 2 5 \pm \mathbf { 0 , 1 7 }}$ & $0,72 \pm 0,84$ & $\mathbf{0 , 0 4}$ \\
\hline $\begin{array}{l}\text { Tento aprender a viver com a } \\
\text { situação }\end{array}$ & $\mathbf{2 , 1 6 \pm 0 , 8 2}$ & $1,65 \pm 0,92$ & $\mathbf{0 , 0 4}$ \\
\hline Estratégias (Focada no emoção) & & & \\
\hline $\begin{array}{l}\text { Fico aborrecido e expresso os } \\
\text { meus sentimentos }\end{array}$ & $\mathbf{1 , 8 3} \pm \mathbf{0 , 5 8}$ & $1,25 \pm 0,98$ & $\mathbf{0 , 0 3}$ \\
\hline
\end{tabular}




\begin{tabular}{l|c|c|c}
\hline & $\begin{array}{c}\text { Exerce } \\
\text { atividade } \\
\text { laboral }\end{array}$ & $\begin{array}{c}\text { Não exerce } \\
\text { atividade } \\
\text { laboral }\end{array}$ & \\
\hline $\begin{array}{l}\text { Tento encontrar conforto } \\
\text { na minha religião ou crença } \\
\text { espiritual }\end{array}$ & $\mathbf{2 , 1 6 \pm 0 , 1 1}$ & $1,32 \pm 1,11$ & $\mathbf{0 , 0 1}$ \\
\hline Rezo ou medito & $\mathbf{2} \pm \mathbf{0}$ & $1,37 \pm 1,12$ & $\mathbf{0 , 0 4}$ \\
\hline $\mathrm{P}^{*} \leq 0,05$ & & & \\
\hline
\end{tabular}

A seguir, a Tabela 7 mostra que no curso de Ciência da Computação, quanto ao sexo, os dados que tiveram relevância significativa indicam que as mulheres, utilizam das estratégias: procuro apoio emocional de alguém $(\mathrm{p}=0,01)$; procuro conforto e compreensão de alguém $(\mathrm{p}=0,007)$; peço conselhos e ajuda a outras pessoas para enfrentar melhor a situação $(p=0,03)$ e também peço conselhos e ajuda a pessoas que passaram pelo mesmo $(\mathrm{p}=0,05)$; sendo estas focadas no problema. Já nas estratégias focadas na emoção, os homens utilizam das estratégias: enfrento a situação levando-a para a brincadeira $(\mathrm{p}=0,04)$; enfrento a situação com humor $(\mathrm{p}=0,01)$ e as mulheres a estratégia rezo ou medito $(\mathrm{p}=0,01)$.

Tabela 7: Dados do curso ciência da computação em relação ao sexo

\begin{tabular}{|c|c|c|c|}
\hline & Masculino & Feminino & \\
\hline Estratégias (Focada no problema) & $\begin{array}{c}\text { Média } \pm \text { Desvio } \\
\text { Padrão }\end{array}$ & $\begin{array}{c}\text { Média } \pm \\
\text { Desvio Padrão }\end{array}$ & $\mathbf{P}$ \\
\hline $\begin{array}{l}\text { Procuro apoio emocional de } \\
\text { alguém }\end{array}$ & $0,74 \pm 0,92$ & $1,8 \pm 1,30$ & 0,01 \\
\hline $\begin{array}{l}\text { Procuro conforto e compreensão } \\
\text { de alguém }\end{array}$ & $0,74 \pm 0,84$ & $1,8 \pm 1,30$ & 0,007 \\
\hline $\begin{array}{l}\text { Peço conselhos e ajuda a outras } \\
\text { pessoas para enfrentar melhor a } \\
\text { situação }\end{array}$ & $1,19 \pm 0,94$ & $2,0 \pm 1,0$ & 0,03 \\
\hline $\begin{array}{l}\text { Peço conselhos e ajuda a pessoas } \\
\text { que passaram pelo mesmo }\end{array}$ & $1,19 \pm 1,03$ & $2,0 \pm 1,0$ & 0,05 \\
\hline \multicolumn{4}{|l|}{ Estratégias (Focada no emoção) } \\
\hline $\begin{array}{l}\text { Enfrento a situação levando-a } \\
\text { para a brincadeira }\end{array}$ & $1,57 \pm 0,97$ & $0,8 \pm 0,83$ & 0,04 \\
\hline Rezo ou medito & $1,40 \pm 1,07$ & $2,6 \pm 0,89$ & 0,01 \\
\hline Enfrento a situação com humor & $1,87 \pm 0,84$ & $1,0 \pm 0,0$ & 0,01 \\
\hline $\mathrm{P}^{*} \leq 0,05$ & & & \\
\hline
\end{tabular}

Para a Fisioterapia, os indivíduos da amostra que não exercem atividade laboral (Tabela 8) utilizam a estratégia: busco outras atividades para me distrair 
da situação $(p=0,0005)$; sendo esta com foco no problema e as estratégias com foco na emoção foram: uso álcool ou outras drogas para me sentir melhor $(\mathrm{p}=0,04)$; simplesmente desisto de tentar atingir o meu objetivo $(\mathrm{p}=0,02)$; faço outras atividades para pensar menos na situação, tal como ir ao cinema, ver $\mathrm{TV}$, ler, sonhar ou ir às compras $(\mathrm{p}=0,0007)$; fico aborrecido e expresso os meus sentimentos (emoções) ( $\mathrm{p}=0,004)$ e enfrento a situação com humor $(\mathrm{p}=0,03)$. Os que exercem atividade laboral utilizam a estratégia: enfrento a situação levando-a para a brincadeira $(\mathrm{p}=0,005)$, com foco na emoção.

Tabela 8: Dados do curso de Fisioterapia em relação ao trabalho

\begin{tabular}{|c|c|c|c|}
\hline & $\begin{array}{l}\text { Exerce } \\
\text { atividade } \\
\text { laboral }\end{array}$ & $\begin{array}{l}\text { Não exerce } \\
\text { atividade } \\
\text { laboral }\end{array}$ & \\
\hline Estratégias (Focada no problema) & $\begin{array}{c}\text { Média } \pm \\
\text { Desvio Padrão }\end{array}$ & $\begin{array}{l}\text { Média } \pm \\
\text { Desvio } \\
\text { Padrão }\end{array}$ & $\mathbf{P}$ \\
\hline $\begin{array}{l}\text { Busco outras atividades para me distrair } \\
\text { da situação }\end{array}$ & $1,29 \pm 0,82$ & $2,13 \pm 0,96$ & 0,0005 \\
\hline \multicolumn{4}{|l|}{ Estratégias (Focada no emoção) } \\
\hline $\begin{array}{l}\text { Uso álcool ou outras drogas para me } \\
\text { sentir melhor }\end{array}$ & $0,12 \pm 0,34$ & $0,34 \pm 0,57$ & 0,04 \\
\hline $\begin{array}{l}\text { Simplesmente desisto de tentar atingir o } \\
\text { meu objetivo }\end{array}$ & $0,35 \pm 0,66$ & $0,78 \pm 0,95$ & 0,02 \\
\hline $\begin{array}{l}\text { Enfrento a situação levando-a para a } \\
\text { brincadeira }\end{array}$ & $1,88 \pm 1,16$ & $0,95 \pm 0,92$ & 0,005 \\
\hline $\begin{array}{l}\text { Faço outras atividades para pensar } \\
\text { menos na situação, tal como ir ao } \\
\text { cinema, ver TV, ler, sonhar ou ir às } \\
\text { compras }\end{array}$ & $0,74 \pm 0,85$ & $1,60 \pm 1,03$ & 0,0007 \\
\hline $\begin{array}{l}\text { Fico aborrecido e expresso os meus } \\
\text { sentimentos (emoções) }\end{array}$ & $1,32 \pm 1,01$ & $2,08 \pm 1,04$ & 0,004 \\
\hline Enfrento a situação com humor & $1,35 \pm 0,98$ & $1,86 \pm 1,05$ & 0,03 \\
\hline $\mathrm{P}^{*} \leq 0,05$ & & & \\
\hline
\end{tabular}

A Tabela 9 apresenta os dados do curso de Fisioterapia em relação ao sexo. Os homens utilizam as estratégias: busco outras atividades para me distrair da situação $(p=0,05)$; tento analisar a situação de maneira diferente, de forma a torná-la mais positiva $(\mathrm{p}=0,05)$; procuro algo positivo em tudo o que está acontecendo $(\mathrm{p}=0,006)$; que são focadas no problema e as estratégias focadas na emoção foram: enfrento a situação levando-a para a brincadeira $(p=0,005)$; faço outras atividades para pensar menos na situação, tal como ir ao cinema, ver $\mathrm{TV}$, ler, sonhar ou ir às compras $(\mathrm{p}=0,04)$. Já para o sexo feminino, 
as estratégias: procuro apoio emocional de alguém $(p=0,02)$; tento aprender a viver com a situação $(p=0,03)$; peço conselhos e ajuda a pessoas que passaram pelo mesmo $(\mathrm{p}=0,03)$; são focadas no problema e as estratégias focadas na emoção foram: sinto e expresso os meus sentimentos de aborrecimento $(\mathrm{p}=$ $0,02)$; fico aborrecido e expresso os meus sentimentos (emoções) $(p=0,04)$; faço críticas a mim mesmo $(\mathrm{p}=0,003)$.

Tabela 9: Dados do curso de Fisioterapia em relação ao sexo

\begin{tabular}{|c|c|c|c|}
\hline & Masculino & Feminino & \\
\hline Estratégias (Focada no problema) & $\begin{array}{l}\text { Média } \pm \\
\text { Desvio } \\
\text { Padrão }\end{array}$ & $\begin{array}{l}\text { Média } \pm \\
\text { Desvio } \\
\text { Padrão }\end{array}$ & $\mathbf{P}$ \\
\hline $\begin{array}{l}\text { Busco outras atividades para me distrair } \\
\text { da situação }\end{array}$ & $2,11 \pm 0,78$ & $1,55 \pm 0,98$ & 0,05 \\
\hline Procuro apoio emocional de alguém & $0,88 \pm 1,05$ & $1,64 \pm 1,06$ & 0,02 \\
\hline $\begin{array}{l}\text { Tenta analisar a situação de maneira } \\
\text { diferente, de forma a torná-la mais } \\
\text { positiva }\end{array}$ & $2,33 \pm 0,86$ & $1,86 \pm 0,76$ & 0,05 \\
\hline Tento aprender a viver com a situação & $1,33 \pm 1,22$ & $1,93 \pm 0,8$ & 0,03 \\
\hline $\begin{array}{l}\text { Procuro algo positivo em tudo o que está } \\
\text { acontecendo }\end{array}$ & $2,55 \pm 0,72$ & $1,6 \pm 1,09$ & 0,006 \\
\hline $\begin{array}{l}\text { Peço conselhos e ajuda a pessoas que } \\
\text { passaram pelo mesmo }\end{array}$ & $1,11 \pm 0,92$ & $1,75 \pm 0,98$ & 0,03 \\
\hline \multicolumn{4}{|l|}{ Estratégias (Focada no emoção) } \\
\hline $\begin{array}{l}\text { Sinto e expresso os meus sentimentos de } \\
\text { aborrecimento }\end{array}$ & $1,33 \pm 0,86$ & $1,97 \pm 0,89$ & 0,02 \\
\hline $\begin{array}{l}\text { Enfrento a situação levando-a para a } \\
\text { brincadeira }\end{array}$ & $1,88 \pm 1,16$ & $0,95 \pm 0,92$ & 0,005 \\
\hline $\begin{array}{l}\text { Faço outras atividades para pensar menos } \\
\text { na situação, tal como ir ao cinema, ver TV, } \\
\text { ler, sonhar ou ir às compras }\end{array}$ & $2,22 \pm 1,09$ & $1,53 \pm 1,05$ & 0,04 \\
\hline $\begin{array}{l}\text { Fico aborrecido e expresso os meus } \\
\text { sentimentos (emoções) }\end{array}$ & $1,33 \pm 1,22$ & $2,0 \pm 1,0$ & 0,04 \\
\hline Faço críticas a mim mesmo & $0,88 \pm 1,16$ & $1,91 \pm 0,94$ & 0,003 \\
\hline $\mathrm{P}^{*} \leq 0,05$ & & & \\
\hline
\end{tabular}

\section{DISCUSSÃO}

Os dados mostram que 90,39\% dos alunos de Ciência da Computação são do sexo masculino, comprovando uma predominância nos cursos de Tecnologia de uma população masculina. Segundo Carvalho (2006) os cursos 
de graduação mais procurados pelos homens são aqueles voltados para as áreas de exatas. Os resultados também indicaram que há maior representatividade do sexo feminino no curso da área da saúde, compondo 83,34\%.

No Brasil, os dados apresentados pelo Instituto Nacional de Estudos e Pesquisas Educacionais Anísio Teixeira (INEP), no resumo técnico da Educação Superior de 2011, mostraram que as mulheres estão matriculadas em sua maioria nos cursos das Ciências Sociais, Humanas e Saúde, já os homens, têm prevalência nas Ciências Exatas e Tecnologias.

Verifica-se espaços marcadamente femininos e masculinos nas escolhas das carreiras profissionais, as mulheres continuam sendo maioria em cursos tradicionalmente femininos, como Serviço Social, Enfermagem, Nutrição, Psicologia, Letras, Pedagogia e demais licenciaturas. (BARBOSA; CARVALHO; FERNANDES, 2013, p. 219-220). Já as carreiras científicas de prestígio na Física, na Matemática, na Computação e nas Engenharias permanecem como campos de conhecimento e de cultura masculinos como afirmam Carvalho e Rabay (2013).

Estas afirmações referentes as escolhas profissionais, podem ser explicadas devido a uma construção do que é entendido pelos papeis da mulher na sociedade, tais como: maternidade, cuidado e proteção com o outro. Estas influências culturais estão presentes não apenas no Brasil, mas também em outros (MORAES, 2012).

Em resposta a nossa hipótese, esta não foi comprovada, pois ficou evidente que quanto maior for o repertório de estratégias, menor será a percepção do nível de stress e também melhor vai lidar com as estratégias acadêmicas e pessoais, independente de qual seja o curso do indivíduo. Quanto ao nosso objetivo, sobre a avaliação da percepção do nível de stress nos universitários, buscamos uma possível relação com o uso de estratégias de coping, observa-se que os alunos do curso de Ciência da Computação utilizam um maior repertório de estratégias (ver Tabela 5) e apresenta uma percepção menor do stress (ver Tabela 4). Já os alunos do curso de Fisioterapia, por apresentar um repertório de estratégias mais restrito (ver Tabela 5), tem uma percepção maior do stress (ver Tabela 3) revelando uma necessidade de ampliação das suas estratégias e assim, espera-se que tenham uma percepção menor do stress.

Verificou-se que as habilidades de coping desempenham um importante papel na percepção do stress, pois quanto mais estratégias adaptativas foram utilizadas para o enfrentamento dos alunos, menores foram os níveis de percepção do stress.

Ao analisar as estratégias, específico do curso de Ciência da Computação, para as pessoas que exercem uma atividade laboral, podemos destacar o uso das seguintes estratégias focadas na resolução de problemas: "procuro conforto e compreensão de alguém" e também "tento aprender a viver com a situação". Ressaltamos que não houve relevância significativa no que diz respeito ao 
uso de estratégias de enfrentamento para os alunos que não exercem alguma atividade laboral.

Quanto aos dados do curso de Fisioterapia em relação a quem exerce atividade laboral, a prevalência foi do uso de estratégias reguladoras da emoção adaptativas (ver Tabela 8), entretanto quem não exerce nenhum tipo de atividade laboral apresentou uso de estratégias focadas na emoção, como enfrentamento de situações com humor e uso de álcool e drogas. Desta forma, os dados evidenciam que o trabalho pode ser considerado um fator protetor. Dentro de uma organização, os sujeitos podem estruturar relações sócio profissionais que permitam vivências de crescimento pessoal, de respeito às regras coletivas e de afetividade, promovendo assim o desenvolvimento de estratégias mais saudáveis no controle do stress.

\section{CONCLUSÃO}

Podemos concluir através desses dados a importância de ter um repertório de estratégias diversificado, ou seja, várias estratégias, para que o discente tenha ferramentas para baixar sua percepção do stress. Também é importante que no ambiente acadêmico, seja desenvolvido projetos de treinamento em estratégias adaptativas, tendo em vista a sobrecarga emocional e física que a população universitária vivencia ao longo do curso, pois fica evidente que quanto maior for o repertório de estratégias, mais saudável será a administração do stress.

Os dados da pesquisa não podem ser desconsiderados, dado que há um grupo significativo de alunos com uma percepção preocupante do stress. Esses alunos, estão se preparando para serem inseridos no ambiente de trabalho e para que eles possam ter um bom desempenho de suas funções, é importante que eles estejam em boas condições de saúde mental.

O aluno que na graduação já fica vulnerável a doença mental, tem maior risco de ter um desempenho profissional reduzido, o que pode ocasionar quadros de depressão, risco para o suicídio e incidência ao uso de álcool e drogas, além de ter uma dificuldade quanto ao processo de aprendizagem e rebaixamento das relações interpessoais. Diante disso, é fundamental que desenvolvam mais pesquisas voltadas para o público universitário com foco na avaliação e treino no controle do stress.

\section{REFERÊNCIAS}

ANTONIAZZI, Adriane S. Desenvolvimento de Instrumentos para a avaliação de coping em adolescentes brasileiros. Instituto de Psicologia, Rio Grande do Sul, nov. 1999. Disponível em <https://www.lume.ufrgs.br/bitstream/ handle/10183/2908/000283149.pdf? sequence=1 >. Acesso em: 13 de abr. de 2017. 
ANTONIAZZI, Adriane S.; DELL'AGLIO, Débora D.; BANDEIRA, Denise R. O conceito de coping: uma revisão bibliográfica. Estudos de Psicologia, Universidade Federal do Rio Grande do Sul, v. 3, n. 2, p. 273-294, 1998.

BARBOSA, R. C., CARVALHO, Maria E.P., FERNANDES, M.O.M. Gênero e Tecnologias da Informação: um olhar sobre a Educação Superior na Paraíba e as possibilidades de promoção da equidade de gênero através da Educação. In: Lópes, Alejandra Montané e Carvalho, Maria Eulina Pessoa de (Coord). Mujeres y educación superior. João Pessoa: Editora da UFPB, 2013.

BORINE, Rita C. C.; WANDERLEY, Kátia S.; BASSITT, Débora P. Relação entre a qualidade de vida e o estresse em acadêmicos da área da saúde. Estudos Interdisciplinares em Psicologia, Londrina, v. 6, n. 1, p. 100-118, jun. 2015. Disponível em <http:/ / pepsic.bvsalud.org/scielo.php?script=sci arttext\&pid=S223664072015000100008\&lng=pt\&nrm=iso $>$. Acesso em: 12 de set. de 2017.

CARLOTTO, Rodrigo C.; TEIXEIRA, Marco A. P.; DIAS, Ana C. G. Adaptação Acadêmica e Coping em Estudantes Universitários. Psicologia USF, Itatiba, v. 20, n. 3, p. 421-432, 2015.

CARVALHO, Maria E. P.; RABAY, Glória. Gênero e Educação Superior: apontamentos sobre o tema. João Pessoa, UFPB, v. 1, n. 1, 2013.

CARVALHO, Marília P. Gênero e carreiras universitárias: o que mudou. Fazendo Gênero, v. 7, p. 1-7, 2006.

DELL'AGLIO, Débora D. O processo de coping em crianças e adolescentes: adaptação e desenvolvimento. Temas em psicologia, Ribeirão Preto, Vol. 11, n. 1, p. 38-45, 2003. Disponível em: <http:/ / pepsic.bvsalud.org/scielo.php?script=sci arttext\&pid=S1413389X2003000100005\&lng=pt\&nrm=iso $>$. Acesso em: 30 de mai. de 2017.

FILGUEIRAS, Julio C.; HIPPERT, Maria I. S. A polêmica em torno do conceito de estresse. Psicologia ciência e profissão, Brasília, v. 19, n. 3, p. 40-51, 1999. Disponível em <http:/ / www.scielo.br/scielo.php?script=sci_arttext\&pid=S141498931999000300005\&lng=pt\&nrm=iso >. Acesso em: 30 de mai. de 2017.

INEP. Censo da educação superior: 2011 - resumo técnico. Instituto Nacional de Estudos e Pesquisas Educacionais Anísio Teixeira. Brasília: INEP, 2013.

LIPP, Marilda E. N.; TANGANELLI, M. S. Stress e qualidade de vida em Magistrados da Justiça do Trabalho: diferenças entre homens e mulheres. Psicologia Reflexão e Crítica, Porto Alegre, v. 15, n. 3, p. 537-548, 2002. Disponível em <http:/ / www.scielo. $\mathrm{br} /$ scielo.php?script=sci_arttext\&pid=S0102-79722002000300008\&lng=pt\&nrm=iso $>$. Acesso em: 26 de set. de 2017.

LIPP, Marilda N. E. O stress está dentro de você. 3. ed. São Paulo: Contexto, 2000. 
MARRAS, Jean P.; VELOSO, Henrique M. Estresse ocupacional. Rio de Janeiro: Elsevier, 2012.

MONTEIRO, Claudete F. S.; FREITAS, Jairo F. Medeiros.; RIBEIRO, Artur A. P. Estresse no cotidiano acadêmico: o olhar dos alunos de Enfermagem da Universidade Federal do Piauí. Escola Anna Nery, Rio de Janeiro, v. 11, n. 1, p. 66-72, mar. 2007. Disponível em <http:/ / www.scielo.br/scielo.php?script=sci_arttext\&pid=S141481452007000100009\&lng=pt\&nrm=iso>. Acesso em: 12 de set. de 2017.

MORAES, Erika. Ser mulher na atualidade: a representação discursiva da identidade feminina em quadros humorísticos de maitena. In: TASSO, Ismara.; NAVARRO, Pedro. Produção de identidades e processos de subjetivação em práticas discursivas. Maringá: Eduem, p. 259-285, 2012.

RAMOS, Fabiana P.; ENUMO, Sônia R. F.; PAULA, Kely M. P. Teoria Motivacional do coping: uma proposta desenvolvimentista de análise do enfrentamento do estresse. Estudos de Psicologia, Campinas, v. 32, n. 2, p. 269-279, jun. 2015. Disponível em <http:/ / www.scielo.br/scielo.php?script=sci_arttext\&pid=S0103-166X2015000200269 \&lng=en\&nrm=iso $>$. Acesso em: 21 de abr. de 2017.

RAMOS, Suzana I. V.; CARVALHO, André J. R. Nível de stress e estratégias de coping dos estudantes do $1^{\circ}$ ano de ensino universitário de Coimbra. Psicologia.pt o portal dos psicólogos, p. 10-20, 2007.

RIBEIRO, José L. P.; RODRIGUES, Antônio P. Questões acerca do coping: a propósito do estudo de adaptação do brief cope. Psicologia, Saúde \& Doenças. Lisboa, v. 5, n. 1, p. 3-15, jul. 2004.

SANTOS, Juliana A. F. et al. Estresse em Acadêmicos do Curso de Fisioterapia. Revista brasileira de ciências humanas, v. 16, n. 2, p. 84-94, 2012.

TEIXEIRA, Rubens F.; AZEVEDO, Helton. Estratégias de combate ao stress: um estudo junto a profissionais de tecnologia de informação. Revista FaaTual. v. 2, n. 2, p. 106126, mai. 2017. 